\title{
Cellulitis of Hand
}

National Cancer Institute

\section{Source}

National Cancer Institute. Cellulitis of Hand. NCI Thesaurus. Code C34454.

Cellulitis of the hand. 